\title{
Amino-acid-based metallo-hydrogel that acts like an esterase
}

Article

Accepted Version

Gayen, K., Basu, K., Bairagi, D., Castelletto, V., Hamley, I. W. and Banerjee, A. (2018) Amino-acid-based metallo-hydrogel that acts like an esterase. ACS Applied Bio Materials, 1 (5). pp. 1717-1724. ISSN 2576-6422 doi:

https://doi.org/10.1021/acsabm.8b00513 Available at https://centaur.reading.ac.uk/80908/

It is advisable to refer to the publisher's version if you intend to cite from the work. See Guidance on citing.

To link to this article DOI: http://dx.doi.org/10.1021/acsabm.8b00513

Publisher: American Chemical Society (ACS)

All outputs in CentAUR are protected by Intellectual Property Rights law, including copyright law. Copyright and IPR is retained by the creators or other copyright holders. Terms and conditions for use of this material are defined in the End User Agreement.

\section{www.reading.ac.uk/centaur}

\section{CentAUR}

Central Archive at the University of Reading 
Reading's research outputs online 


\section{An amino acid based metallo-hydrogel that acts}

\section{like an esterase}

KousikGayen, ${ }^{\dagger}$ KingshukBasu, ${ }^{\dagger}$ DipayanBairagi, ${ }^{\dagger}$ Valeria Castelletto, ${ }^{\#}$ Ian W. Hamley ${ }^{\#}$ and Arindam Banerjee ${ }^{* \dagger}$

${ }^{\dagger}$ Department of School of Biological Sciences, Indian Association for the Cultivation of Science, Jadavpur, Kolkata-700032, India. Fax: (+91)332473-2805. E-mail: bcab@iacs.res.in

\#Department of Chemistry, University of Reading, Whitenights, Reading, RG6, 6AD, UK.

KEYWORDS: Histidine based amphiphile.Self-assembly .Metallo-hydrogel .Ester hydrolysis .Esterase activity

\section{ABSTRACT}

A histidine based amphiphile containing a C14 fatty acyl chain, N-histidyl $\mathrm{N}^{\prime}$-myristry ethyl amine (AM1, 14.7mM) forms hydrogels in the presence of $\mathrm{Fe}^{3+}$ (within the range 1.47 to $4.41 \mathrm{mM}$ ) and $\mathrm{Hg}^{2+}$ (within the range 3.67 to $11.02 \mathrm{mM}$ ) ions in aqueous dispersions at $\mathrm{pH} 6.6$ $\left(27^{\circ} \mathrm{C}\right)$. The imidazole ring of the histidine residue plays a vital role to interact with these metalions. The thermal and mechanical stability of these metallo-hydrogels can be tuned by changing the proportion of amphiphile to metal ion ratio (1:0.1 to 1:0.3 for $\mathrm{Fe}^{3+}$ containing gel and 1:0.25 to $1: 0.75$ for $\mathrm{Hg}^{2+}$ containing gel). The metallo-hydrogels were characterized by different spectroscopic and microscopic techniques, low- and wide-angle powder X-ray diffraction and small-angle X-ray scattering studies. FT-IR and NMR spectroscopic studies indicate the 
participation of the imidazole ring in metal-ion binding. Low- and wide-angle powder X-ray diffraction and small-angle X-ray scattering data are in favour of a layered structure of the supramolecular assembly of the AM1 in presence of metal-ions. Both, the amphiphiles and the metal ion induced hydrogels reveal catalytic activity of $p$ - nitrophenyl esters hydrolysis for the acetyl, $n$-butyl and $n$-octyl esters. Ferric ion containing metallo-hydrogel exhibits higher catalytic activity than the corresponding AM1 aggregate in the absence of metal-ions.

\section{INTRODUCTION}

The assembly of small molecules to form functional aggregates has drawn considerable attention for more than a decade ${ }^{1-8}$. This is not only due to the interesting nano-structures that are formed from the assembly of small molecules but also due to the fact that these supramolecular entities form functional hydrogels under suitable conditions. Gels are endowed with a variety of activities $^{9}$ including use as vehicles for drug delivery ${ }^{10-14}$, removal of pollutants and toxic metal ions from waste water $^{15-18}$, tissue engineering ${ }^{19-21}$, making functional nano-hybrid systems ${ }^{22-}$ ${ }^{24}$ and biocatalysts ${ }^{25-27}$. There are many examples of functional hydrogel based on amino acids, peptides, carbohydrates and other biomolecules ${ }^{28-31}$. Small molecules form gels by simple noncovalent cross linking and during the course of assembly many factors control such cross linking process. ${ }^{32}$ Metal ions are good candidates for promoting such cross linking. Steed and coworkers prepared $\mathrm{Ag}^{+}$containing hydrogel with nanofibrous structure for the synthesis of silver nano-particles ${ }^{33}$. There are several examples of metal assisted low molecular weight hydrogels. Amino acids and peptides are good candidates for chelating metal ions using various functional groups present in their side chains.However, examples of amino acid or short peptide based metallo-hydrogels are relatively scarce ${ }^{34,35}$. Liu and coworkers have reported a $\mathrm{Cu}^{2+}$-selective histidine containing bola-amphiphilicmetallo-hydrogel that shows good tolerance towards 
concentrated acid environment and it exhibits very good selectivity towards $\mathrm{Cu}^{2+}$ ions ${ }^{36}$. Banerjee and co-workers have reported tyrosine containing metallohydrogel with multiple stimuli responsiveness ${ }^{37}$. The nature of self-assembly and functionality of peptides can be regulated by ligating with suitable metal ions ${ }^{38}$. It has been found that self-assembled synthetic peptides are good candidates for catalyzing various organic transformations ${ }^{39,40}$.It is known that the activity of enzyme enormously increases in the presence of a metal ion as a co-factor. Esterase belongs to a useful category of enzymes that plays an important role to break down the drugs into corresponding smaller fragments inside the body ${ }^{41}$. To mimic the function of an enzyme activity by using a small molecule remains a great challenge to the chemist as Nature has optimized enzymes over aeonsof evolutionary time. Several research groups have reported metal nanoparticles $^{42-45}$, dendrimers ${ }^{46,47}$, micelles ${ }^{48,49}$ and others with an ability to catalyse ester hydrolysis. However, the efficiencies of these materials are not very high due to the absence of enzyme-like specific active site for catalysis. Escuder and co-workers have reported an imidazole appended short peptide based hydrogel that shows an enzyme-like activity (esterase activity $)^{50}$.Stupp and co-workers have reported a histidine-containing peptide amphiphilic hydrogel as a catalyst and they showed that hydrolytic reactions can take place on the surface of nanofibers due to the higher number of active sites $^{51}$. Some research groups have studied the esterase activity by using histidine and arginine based co-assembled peptide as a catalyst ${ }^{52,53}$. There are a few reportson the histidine containing short peptide based hydrogelatorswith esterase activity $^{54-58}$. Korendovychand coworkers have reported a $\mathrm{Zn}^{2+}$ ion stabilized amyloid fibril with esterase acivity, whose catalytic activity drops several times in absence of the metal $\operatorname{ion}^{59}$.Therefore, it is of great interest to make amino acid/peptide based molecules with a ligating group that can bind with a suitable metal ion like $\mathrm{Fe}^{3+}, \mathrm{Hg}^{2+}, \mathrm{Cu}^{2+}, \mathrm{Zn}^{2+}$ and any of these metal 
complexes can eventually self-associate by using various non-covalent interactions to form either gels or soluble aggregates. It is a challenging task to construct metallogel based soft, functional materials with appropriate functionality and a suitable metal ion that can show catalytic activity. In the course of our continued interest to study of self-assembling behavior of peptide/amino acid based amphiphilic molecule, N-histidyl N'-myristry ethyl amine (AM1)(Figure 1a)has been designed and synthesized ${ }^{60}$ in such a way that it contains a histidine residue (imidazole ring) to bind transition metal ions, an amide group for intermolecular hydrogen bonding interaction and a fatty acyl chain to promote hydrophobic interaction. This amino acid based amphiphileAM1 binds with $\mathrm{Fe}^{3+}$ and $\mathrm{Hg}^{2+}$ ions separately and under suitable condition it forms a hydrogel at $\mathrm{pH}$ $6.6\left(27^{\circ} \mathrm{C}\right)$. However, the amino acid based molecule alone fails to form a gel under similar and other tested conditions. To the best of our knowledge there is no report of metallo-hydrogel that act as a catalyst for ester hydrolysis. We are curious to investigate whether this histidine-based metal complex can able to act as a biocatalyst or not. Interestingly, the ferric ion based hydrogel shows an esterase-like activity towards a series of $p$-nitrophenyl esters.

\section{EXPERIMENTAL SECTION}

L-Histidine, Myristicacid were purchased from Sigma Aldrich. Ethylene diamine, HOBt (1hydroxybenzotriazole), DCC (N, N'-Dicyclohexylcarbodiimide), p-nitrophenyl acetate (PNPA), p-nitrophenyl butyrate (PNPB), p-nitrophenyloctanoate (PNPO) were purchased from SRL, India.Instrumentation details and spectroscopic analysis are given in the Supporting Information. 


\section{RESULTS AND DISCUSSION}

\section{Gelation Study:}

The histidine based amphiphileN-histidyl $\mathrm{N}^{\prime}$-myristry ethyl amine(AM1) has been synthesized ${ }^{60}$, purified, characterized (Supporting Information) and it has been tested for gelation in aqueous medium ( $\mathrm{pH} 6.6$ at $27^{\circ} \mathrm{C}$ ). For the gelation study, $6 \mathrm{mg}$ of AM1 was taken in a glass vial and dissolved in $1 \mathrm{ml}$ milli-Q water bycarefully heating on a hot plate. A transparent clear solution was observed upon heating, as the system attained room temperature a white colored suspension was formed,this result indicates thatAM1 has no gelation ability in water alone. From the structure of the AM1(Figure 1a) it can be seen that a deprotected amine group of N-terminus and imidazole group of histidine residue are present at the polar head group of the amphiphile. Among all the amino acids, it is well known that histidine has the strongest affinity towards coordination with various metal ions which may eventually affect the nature of self-assembly and the gelation tendency of a molecule. In this context, metal ions like $\mathrm{Mn}^{2+}, \mathrm{Fe}^{2+}, \mathrm{Fe}^{3+}, \mathrm{Co}^{2+}$, $\mathrm{Ni}^{2+}, \mathrm{Cu}^{2+}, \mathrm{Zn}^{2+}, \mathrm{Ag}^{+}, \mathrm{Cd}^{2+}, \mathrm{Hg}^{2+}$ added to the warm solution of the amphiphile to see whether they can form metallogels. Interestingly, it was found that the addition of a measured amount of $\mathrm{Fe}^{3+}$ ions into the warm solution of the amphiphileAM1 resulted in the formation of a brown solution indicating the formation of metal complex. Binding with $\mathrm{Hg}^{2+}$ ions, however, led to formation of awhite suspension. A self-supporting hydrogel was obtained after cooling down the hot solutions of these metal complex to room temperature $\left(27^{\circ} \mathrm{C}\right)$ slowly. At a fixed gelator concentration $(14.74 \mathrm{mM})$ the molar ion ratio of $\mathrm{Fe}^{3+} / \mathrm{Hg}^{2+}$ ion was changed separately to findout the exact AM1 to metal ion ratio to form a stable gel. It was found that AM1 to metal ion ratio was 1:0.1 to $1: 0.3$ for $\mathrm{Fe}^{3+}$ containing gel and 1:0.25 to $1: 0.75$ for $\mathrm{Hg}^{2+}$ containing gel to form. 
The gel melting temperature (Tgel) and minimum gelation concentration (MGC) of these metallo-hydrogels were measured fordifferent proportions of amphiphileAM1 to metal ion (Table S1).

(a)

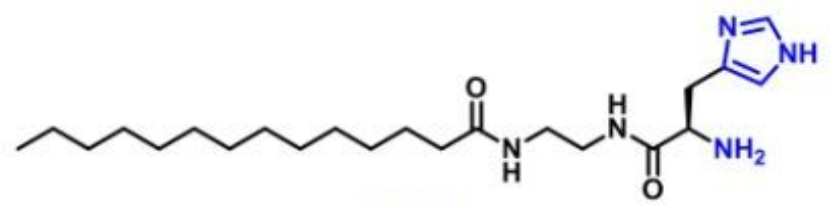

AM1

(b)

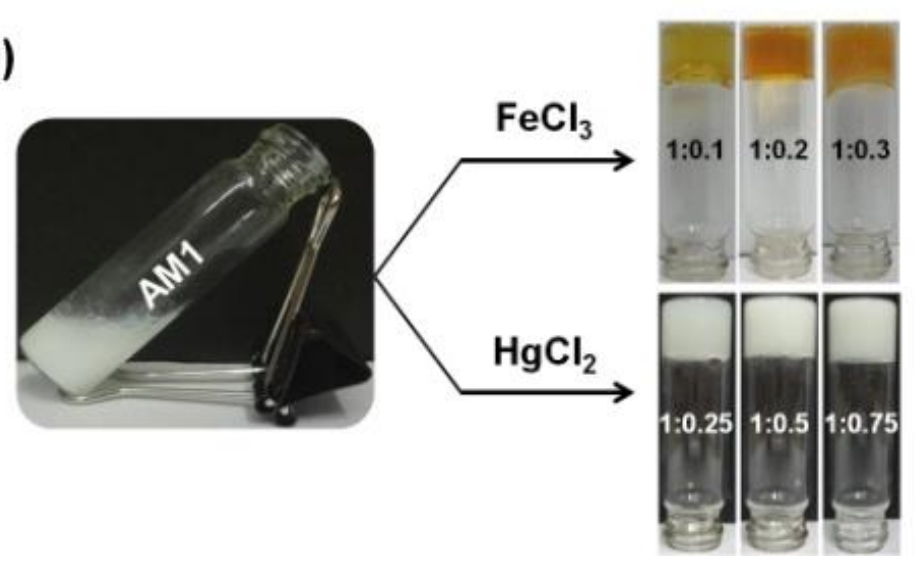

Figure 1: (a) Chemical structure of amphiphileAM1; (b) $\mathrm{FeCl}_{3}$ and $\mathrm{HgCl}_{2}$ induced hydrogel of compound AM1.

\section{Morphological Study:}

Field-emission scanning electron microscopy (FE-SEM) experiments were carried out to image the structure of the self-assembled aggregates and metallo-hydrogels are formed by amphiphileAM1. From the SEM images (Figure $2 \mathrm{a}$ and $2 \mathrm{~b}$ ) it was found that the soluble aggregates ofAM1 in water shows self-assembled helical fiber with approximately 50-80 nm thickness. These helical fibers form locally branched (diverging from a common point) aggregated structures upon assembly (Figure 2a and 2b) with a lesser degree of entanglement. This may be a reason behind the lack of gelation ability of the corresponding compound. 
Interestingly, $\mathrm{Hg}^{2+}$ and $\mathrm{Fe}^{3+}$ mediated gels show highly entangled nanostructures that are moreinterdigitated with each other throughout the space and drastically different from the corresponding aggregates (Figure 2c, 2d). The thickness of gel nanofibers obtained from $\mathrm{Hg}^{2+}$ containing gel varies from $30-50 \mathrm{~nm}$ and the thickness of nanofibers in the $\mathrm{Fe}^{3+}$ ion containing gel is in the range of $30-50 \mathrm{~nm}$. Both of these fibers are non-helical long straight fibers. Therefore, the metal ions have a key role in morphological feature of AM1aggregates and addition of these metal ions reorganizes the aggregates, by breaking its initial helical packing to form highly interdigitated an entangled network structure to form gel.
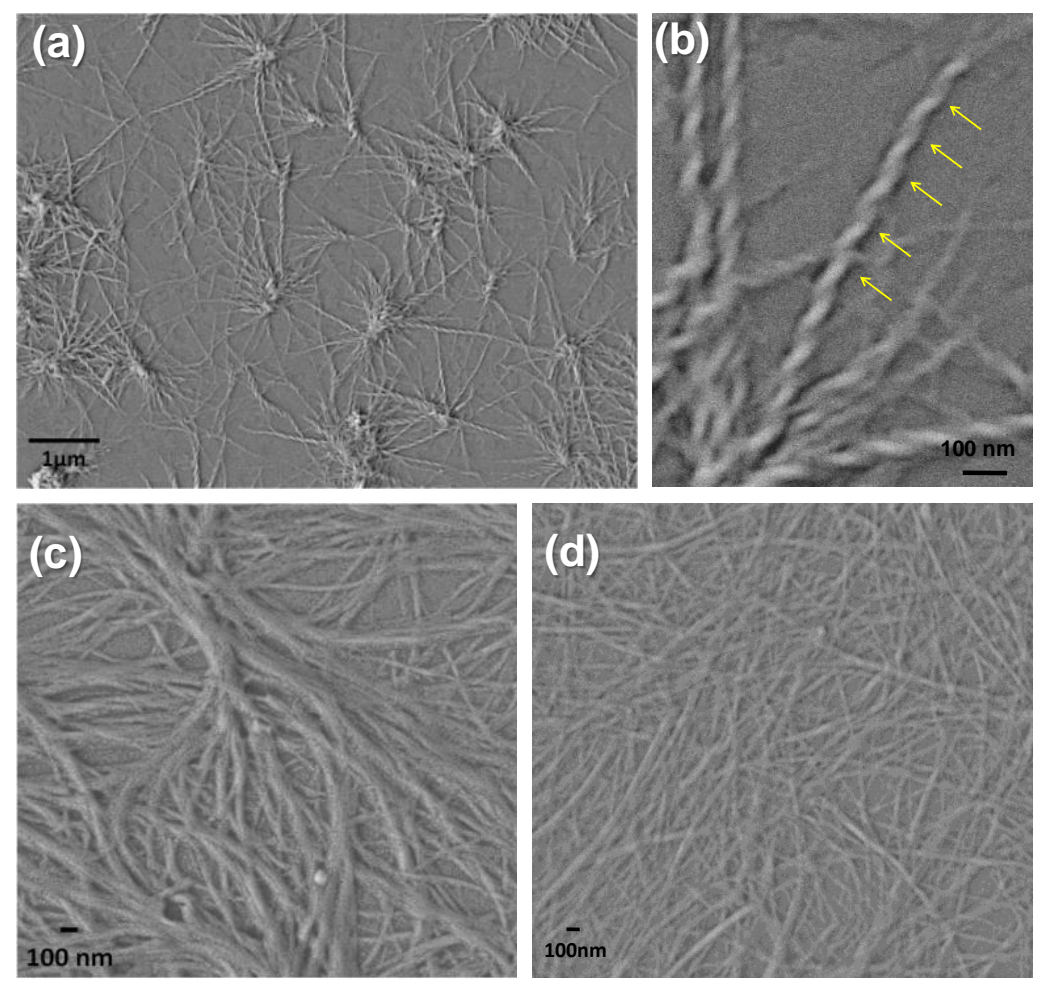

Figure 2: FE-SEM images of (a) Helical fibers form locally branched (diverging from a common point) of aggragated AM1; (b) Enlarged image of helical fibers of aggragated AM1(yellow arrow indicates the pitch of helical fiber ; (c) and (d) $\mathrm{Hg}^{2+}, \mathrm{Fe}^{3+}$ triggered gel respectively.

\section{Fourier Transform Infrared (FT-IR) Analysis:}


FT-IR studies of the dried aggregates and gels reveal the difference in packing pattern of the molecules in the corresponding states. It can be seen from the Figures (S4 and S5) that the aggregate has different FT-IR peaks with respect to the corresponding gels. The FT-IR peaks for the aggregated AM1, at $\bar{v}$ values 1548, 1644 and $3316 \mathrm{~cm}^{-1}$ range can be assigned to amide N-H bending modes, stretching of amide $\mathrm{C}=\mathrm{O}$ and stretching of $\mathrm{H}$-bonded amide $\mathrm{N}-\mathrm{H}$ modes respectively. Interestingly, upon gelation of AM1 in presence of $\mathrm{Hg}^{2+}$ and $\mathrm{Fe}^{3+}$, new peaks appeared in the spectra at $1660 \mathrm{~cm}^{-1}$. The peak at $1660 \mathrm{~cm}^{-1}$ is due to weakly H-bonded amide $\mathrm{C}=\mathrm{O}$. With an increase in the proportion of metal ions the new peak $\left(1660 \mathrm{~cm}^{-1}\right)$ is found to be more prominent in the FT-IR spectra. This indicates the formation of a metal complex in the gel.

\section{Powder X-ray Diffraction (PXRD) Studies:}

To probe the molecular packing arrangement within the self-organized system, small and wideangle powder X-ray diffraction studies (PXRD) of the dried samples were carried out (for the aggregate suspension and two gels). The small angle intensity profile of aggregated compound AM1 shows a peak at $d=45.72 \AA\left(2 \theta=1.88^{\circ}\right)$ which is greater than the calculated molecular length 24.6̊̊(obtained from ChemBioDraw 3D software) but less than the doubleof this length (49.2 $\mathrm{A}$ ) (Figure 3a). This indicates slight intercalated nature of compound AM1 in the aggregated state. The peaks corresponding to $\mathrm{d}=8.41 \AA\left(2 \theta=10.23^{\circ}\right), \mathrm{d}=4.35 \AA\left(2 \theta=19.82^{\circ}\right)$ can be assigned to the inter-sheet and inter-strand distance of a $\beta$-sheet-like structure of the aggregated molecule AM1 $^{61}$ (Figure $\left.3 b\right)$. The intense peak corresponding to $d=3.99 \AA\left(2 \theta=21.64^{\circ}\right)$ can be assigned to highly organized $\pi-\pi$ stacking of aromatic imidazole moieties. Interestingly, upon metal ion induced gelation, a change in PXRD pattern was observed for the xerogels. The $\mathrm{Fe}^{3+}$ containing xerogel shows a peak at $d=25.28 \AA\left(2 \theta=3.40^{\circ}\right)$ in the small-angle PXRD region almost equal 
to the calculated molecular length (Figure 3c). In the wide-angle region, peaks were found at $\mathrm{d}=$ $7.18 \AA\left(2 \theta=11.99^{\circ}\right), \mathrm{d}=4.15 \AA\left(2 \theta=20.78^{\circ}\right)$ can be assigned to the inter-sheet and inter-strand distance of a $\beta$-sheet-like structure and $\mathrm{d}=3.75\left(2 \theta=23.07^{\circ}\right)$, that can be assigned to $\pi$ - $\pi$ stacking distances between aromatic imidazole moeities (Figure 3d). From the above observations we conclude that upon the addition of metal ions a change in molecular arrangement happens in the aggregates and this ultimately leads to gelation. However, no PXRD pattern was obtained from the $\mathrm{Hg}^{2+}$ containing gel.

(a)

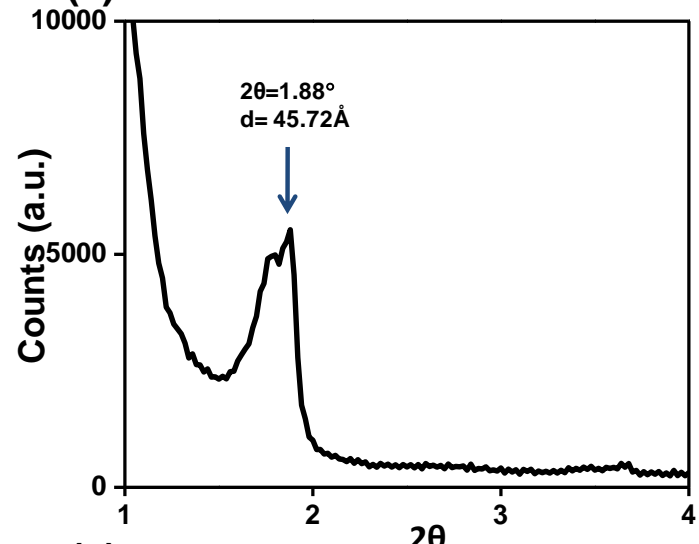

(c)

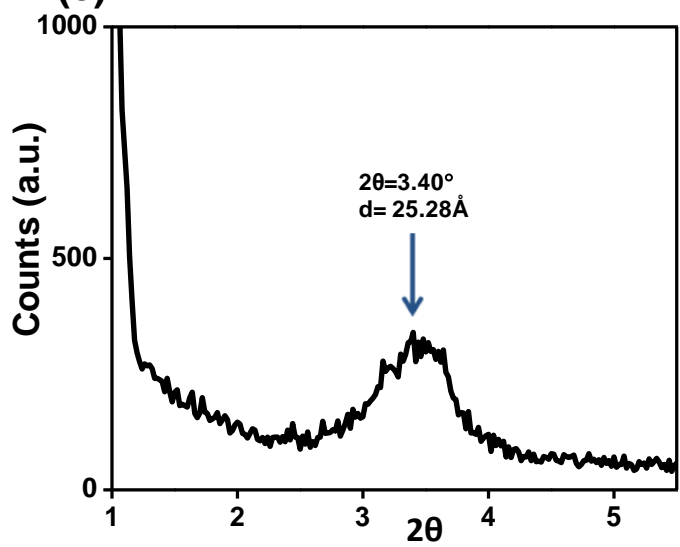

(b)

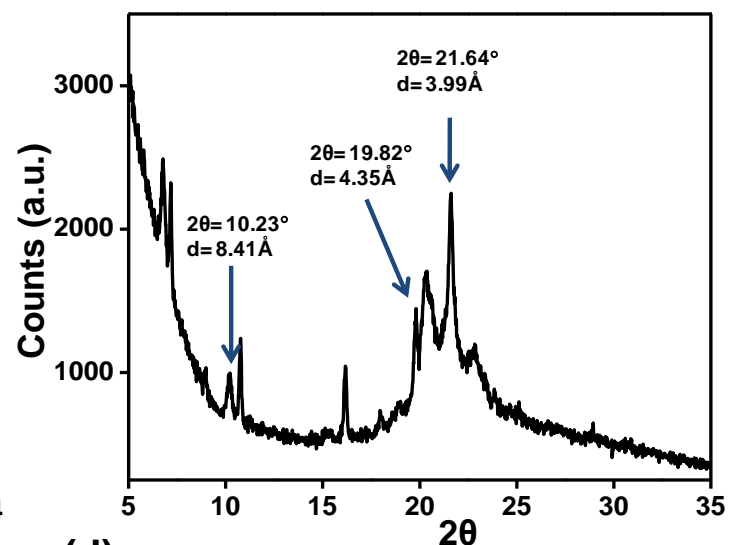

(d)

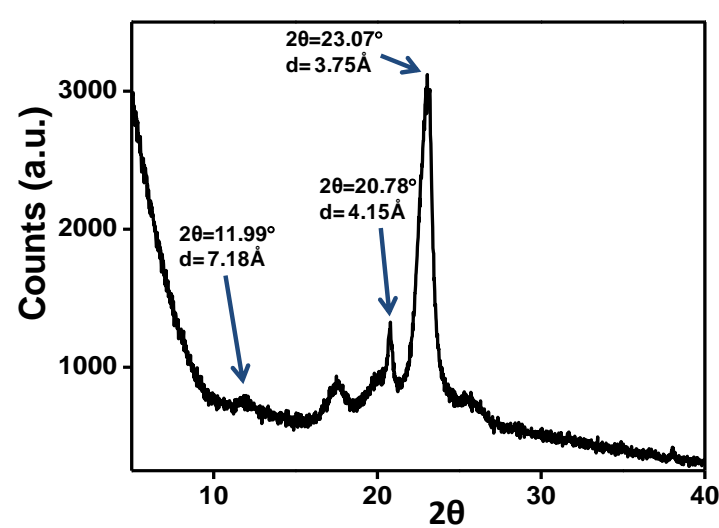


Figure 3: (a) Low (b) Wide-angle X-ray diffraction pattern of xerogel obtained from aggregated AM1. (c) Low-angle (d) Wide-angle X-ray diffraction pattern of xerogel obtained from $\mathrm{Fe}^{3+}$ ion induced hydrogel.

\section{Small-angle X-ray scattering (SAXS) Study:}

To evaluate single molecular length as well as packing pattern of the gel state of $\mathrm{Hg}^{2+}$ induced self-assembled system, small angle X-ray scattering (SAXS) was carried out. The peaks at $\mathrm{d}=44.4 \AA$ and $22.4 \AA$ (Figure S6) can be assigned to a layered structure of interdigitated molecules of compound AM1 in presence of $\mathrm{Hg}^{2+}$. Based on SAXS and PXRD studies a probable model of molecular packing pattern of the gel phase has been constructed in Figure S7.

\section{Determination of binding mode of the amphiphilic molecule AM1 with metal ions:}

To interpret the binding mode of $\mathbf{A M 1}$ with $\mathrm{Hg}^{2+}$ and $\mathrm{Fe}^{3+}$ separately, ${ }^{1} \mathrm{H}$ NMR spectroscopic experiments were carried out for solutions/suspensions and xerogels of metal ion induced AM1 in DMSO- $\mathrm{d}_{6}$ solvent. The chemical shifts $(\delta)$ of proton attached to $\mathrm{C} 2$ and $\mathrm{C} 4$ in imidazole ring of AM1 are observed at $7.50 \mathrm{ppm}$ and $6.79 \mathrm{ppm}$. We expected that the chemical shift $(\delta)$ of these two protons of imidazole ring will be shifted to a downfield position upon metal coordination. From the NMR spectrum it was seen that the chemical shift $(\delta)$ of $\mathrm{C} 2$ and $\mathrm{C} 4$ protons were shifted to7.82, $7.04 \mathrm{ppm}$ and 8.02 and 7.21ppm for $\mathrm{Hg}^{2+}$-containing gel and $\mathrm{Fe}^{3+}$-containing gels respectively (Figure S8). So, it can be concluded that the $\mathrm{sp}^{2}$ nitrogen of imidazole ring directly coordinates to the metal ion. Another coordinating group, $\mathrm{NH}_{2}$ is also present in the amphiphileAM1. The binding of free $\mathrm{NH}_{2}$ of $\mathbf{A M 1}$ with metal ions was determined from the FTIR spectroscopy in dimethylsufoxide solution (DMSO) (Figure S9). In DMSO the AM1 as well 
as two metal complexes of AM1 were clearly soluble and this indicates a monomeric nature of the AM1 and its metal complexes. So, stretching frequencies arise from the self-assembled system (hydrogen bonded N-H stretching, N-H bending) of AM1, will be absent in this case. The peak appears in the spectra of AM1 at $3315 \mathrm{~cm}^{-1}$ is only for $\mathrm{N}-\mathrm{H}$ stretching of free $\mathrm{NH}_{2}$ of AM1. But for two metallo-hydrogels the peak at $3315 \mathrm{~cm}^{-1}$ was diminished completely (Figure S9). So, we can conclude that free $\mathrm{NH}_{2}$ group of $\mathbf{A M 1}$ is directly involved for the coordination to the metal.

\section{Rheological Studies:}

To investigate the mechanical strength as well as viscoelastic behavior of the metallo-hydrogels, rheological measurements were performed at a given concentration $(19.65 \mathrm{mM})$. The frequency sweep experiment was carried out as a function of angular frequency and it was found that the storage modulus $\left(G^{\prime}\right)$ is always greater than the loss modulus $\left(G^{\prime \prime}\right)$, consistent with gel formation. The storage modulus $\left(\mathrm{G}^{\prime}\right)$ and loss modulus $\left(\mathrm{G}^{\prime \prime}\right)$ are both largely independent of frequency, indicating the formation of a stable gel (Figure 4).
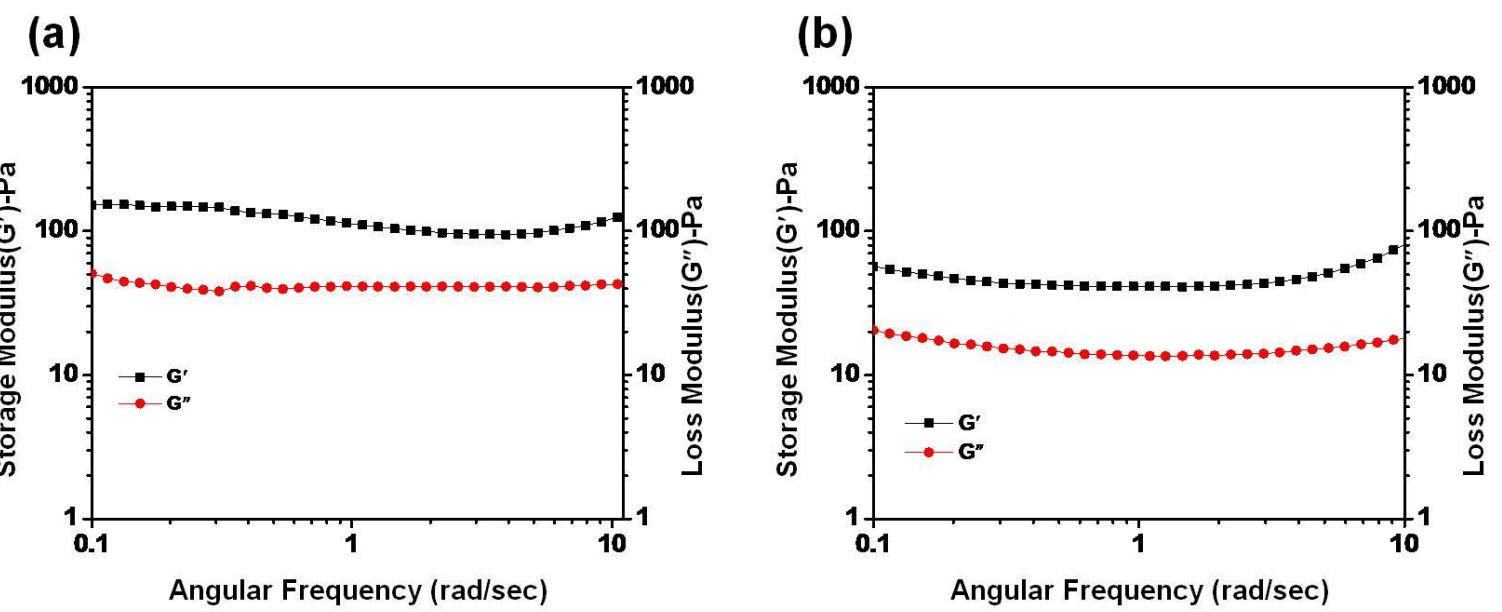
Figure 4: Frequency sweep analysis of (a) $\mathrm{Fe}^{3+}$ ion induced hydrogel obtained from AM1 at the AM1: $\mathrm{Fe}^{3+}(1: 0.25)$ and (b) $\mathrm{Hg}^{2+}$ ion induced hydrogel obtained from AM1 at the AM1: $\mathrm{Hg}^{2+}$ $(1: 0.5)$ at a constant strain of $1 \%$.

\section{Circular Dichroism (CD) study:}

Circular dichroism is an important tool to measure chirality of peptide/amino acid based supramolecular polymers. CD spectra of aggregated AM1, Fe-AM1 and Hg-AM1 (Figure S10) at a fixed concentration of $50 \mu \mathrm{M}$ reveal supramolecular chirality of the corresponding aggregated states.AM1 in aggregated solution phase shows a strong negative peak at around 208 $\mathrm{nm}$ and a positive peak at $234 \mathrm{~nm}$, indicating the presence of supramolecular chirality in the aggregated state. Interestingly, upon gelation in presence of $\mathrm{Fe}^{3+}$ and $\mathrm{Hg}^{2+}$ we get almost featureless CD spectra and it is devoid of any kind of positive or negative Cotton effect. This data is also in agreement with our previous observation in FE-SEM images in which AM1 was found to form chiral helical fibres whereas,Fe-AM1 and Hg-AM1 form straight fibres with no helical pitch.

\section{Studies on esterase activity:}

The histidine containing amphiphile (AM1) self-assembles to produce a metal induced hydrogel. Interestingly, the amphiphilic compound AM1 and ferric ion containing gel of AM1 show esterase-like activity and this was checked by taking a series of $p$-nitrophenyl esters as a model substrate. The catalyst was used in dried form and it was prepared by freeze drying the aggregated solution and $\mathrm{Fe}^{3+}$ containing gel (in a molar ratio of 1: 0.25) of AM1. The catalytic activity was not studied for the $\mathrm{Hg}^{2+}$ ion induced hydrogel due to the toxic and hazardous nature of particular this ion. The progress of the reaction was monitored quantitatively by UV-vis 
spectroscopy as the hydrolysis of $p$-nitrophenyl esters ( $\mathrm{n}=0$ for $p$-nitrophenyl acetate, $\mathrm{n}=2$ for $p$ nitrophenylbutyrate, $\mathrm{n}=6$ for $p$-nitrophynyloctanoate, figure 5) leads to the formation of a yellow colored chromogenic compound p-nitrophenol (Figure 5),with astrong absorption maxima at 400 $\mathrm{nm}$. The stock solution of $p$-nitrophenyl esters was prepared by dissolving it in minimum amount of acetonitrile. Then an appropriate amount of $p$-nitrophenyl esters(n=0 for $p$-nitrophenyl acetate, $\mathrm{n}=2$ for butyrate and $\mathrm{n}=6$ for octanoate) solution was added to the catalytic solution so that final concentration of $p$-nitrophenyl esters was within the range $0.5 \mathrm{mM}$ to $4 \mathrm{mM}$. The reaction mixture was stirred and at a fixed time interval the absorbance value of product formation $(p$ nitrophenol) was recorded. The molar extinction coefficient $(\varepsilon)$ of $p$-nitrophenol was $14011 \mathrm{M}^{-}$ ${ }^{1} \mathrm{~L}^{-1}$, and it was determined by plotting the absorbance versus concentration of $p$-nitrophenol (Figure S11). All the hydrolysis experiments were carried out under the same condition in aqueous phosphate buffer solution $(50 \mathrm{mM})$ at physiological $\mathrm{pH} 7.46\left(27^{\circ} \mathrm{C}\right)$ and in the presence of excess water. Therefore, it can be considered that the hydrolysis reaction was always first order with respect to the substrate ${ }^{62}$. The 0.1 mMcatalytic solution of aggregated AM1 and $\mathrm{Fe}^{3+}$ ion containing gel were prepared in $20 \mathrm{ml}$ phosphate buffer solution $(50 \mathrm{mM})$ of $\mathrm{pH} 7.46$ at $27^{\circ} \mathrm{C}$. These two catalytic solutions were heated on a hotplate to dissolve completely and $2 \mathrm{ml}$ of solution was taken in the reaction vial.

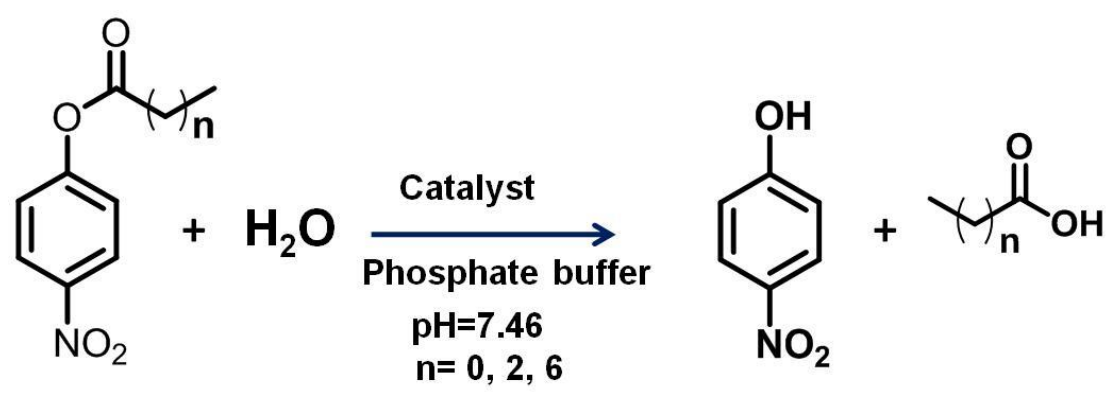


Figure 5: Hydrolysis reaction of $p$-nitrophenyl esters ( $\mathrm{n}=0$ for $p$-nitrophenylacetate[PNPA], $\mathrm{n}=2$ for butyrate[PNPB] and $\mathrm{n}=6$ for octanoate [PNPO])catalyzed by aggregated AM1/ $\mathrm{Fe}^{3+}$ ion induced hydrogel of AM1.

It was found that the absorbance value of the hydrolyzed product, $p$-nitrophenol for the ferric ion based catalyst was sharply increased with a steeper slope as a function of time compared to that of the aggregated AM1 (Figure 6). Therefore it can be concluded that the rate of reaction of ferric ion based catalyst is higher than that of aggregated AM1alone. There was no significant change of the product formation in presence of only $\mathrm{FeCl}_{3}$ solution. Therefore, $\mathrm{FeCl}_{3}$ on its own does not stimulate the hydrolysis reaction.
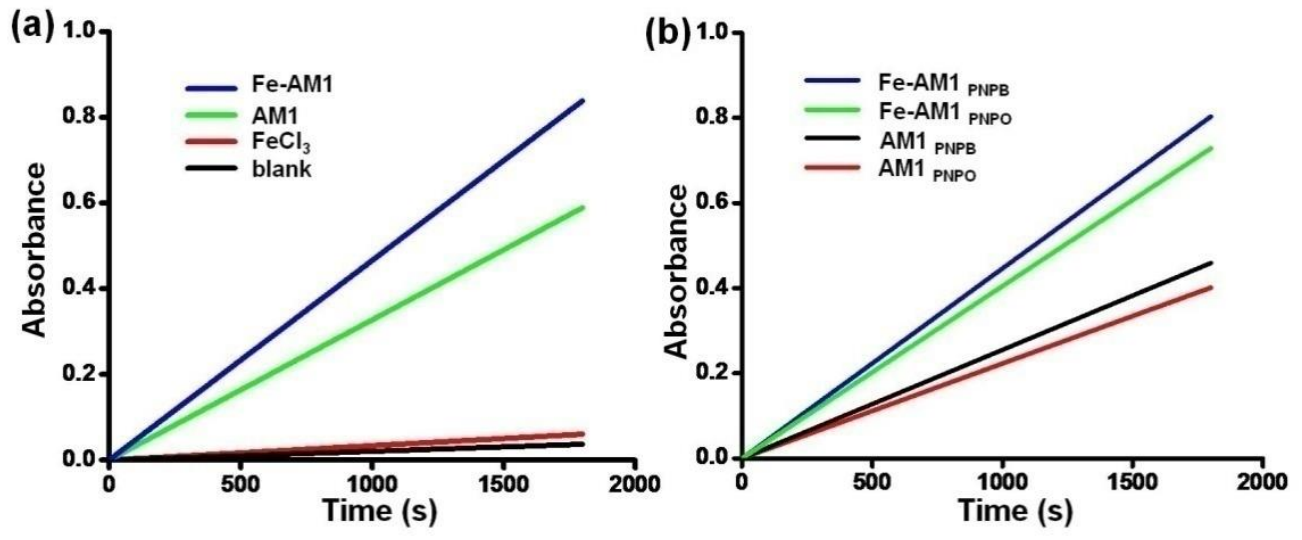

Figure 6:Plot of Absorbance versus time for hydrolysis reaction of $1 \mathrm{mM}(\mathrm{a})$-nitrophenyl acetate(PNPA) and (b) p-nitrophenyl butyrate (PNPB) and p-nitrophenyloctanoate (PNPO) in presence of $0.1 \mathrm{mM}$ catalyst.

The initial hydrolytic reaction rate of $p$-nitrophenyl esters was calculated by varying the substrate concentration keeping the concentration of the catalyst fixed. The Michaelis-Menten kinetic parameters of ester hydrolysis ware calculated from double-reciprocal plots of initial reaction rate versus different concentrations of substrate (Figure 7 and Figure 8). The hydrolytic rate 
constant $\left(\mathrm{K}_{\text {cat }}\right)$, catalytic efficiency $\left(\mathrm{K}_{\text {cat }} / \mathrm{K}_{\mathrm{M}}\right)$ for $\mathrm{Fe}^{3+}$ ion based catalyst and aggregated AM1 were found to be $2.82 \times 10^{-2} \mathrm{~s}^{-1}, 0.63 \mathrm{M}^{-1} \mathrm{~s}^{-1}$ and $1.27 \times 10^{-3} \mathrm{~s}^{-1}, 0.89 \mathrm{M}^{-1} \mathrm{~s}^{-1}$ respectively for the hydrolysis of $p$-nitrophenyl acetate (PNPA) (Table 1). The enhancement of rate constant was 22 times higher for the ferric ion based catalyst with respect to the aggregated AM1. It can be said that the imidazole moiety is not solely responsible for this kind of rate enhancement, however, the combination of ferric ion with the imidazole moiety in self-assembled system plays a vital role in catalysis.
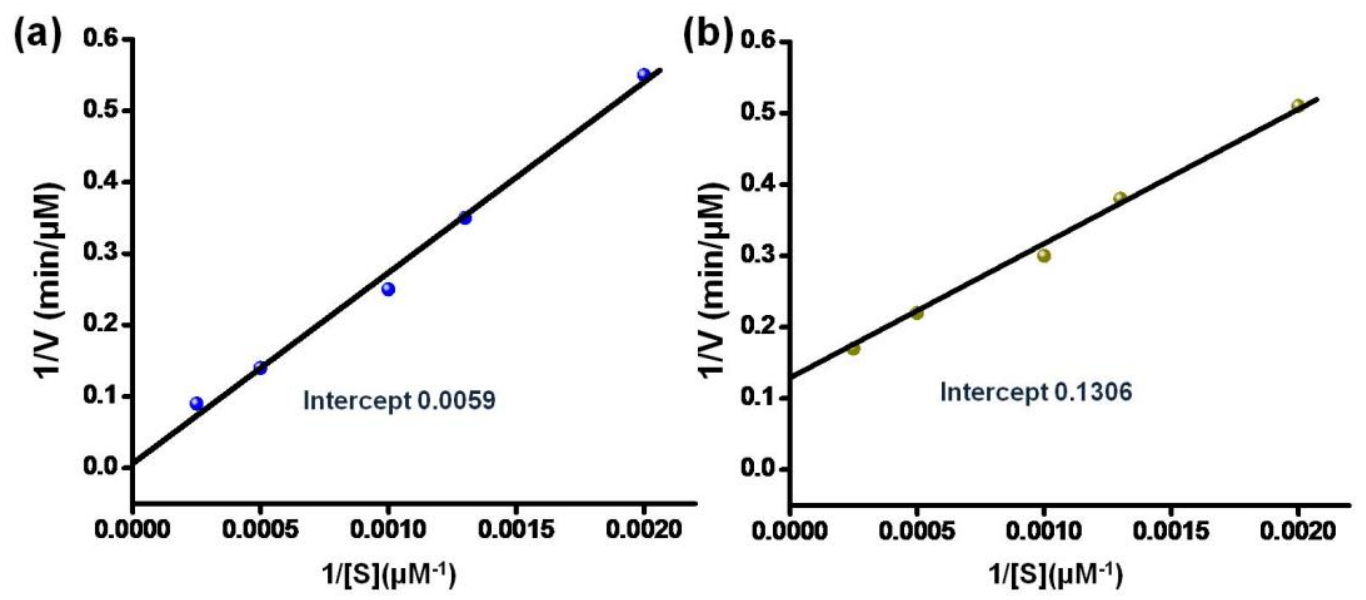

Figure 7:Lineweaver-Burk plot for hydrolysis of $p$-nitrophenyl acetate (PNPA) catalyzed by (a) ferric ion based hydrogeland (b) aggragatedAM1.

The kinetic parameters for other two substrates p-nitrophenyl butyrate and pnitrophenyloctanoate are listed in Table 1. All values of kinetic parameters of these two substrates were found to be lower compared to $p$-nitrophenyl acetate.The possible reason for that is the aggragetion behavior of these two substrates in the phosphate buffer due to the presence of 
long acyl chains. As a result, fewer reacting substrate molecules may come into contact with the reactive center of self-assembled metal catalyst leading to lower reaction rate compared to the $p$ nitrophenyl acetate.

We also carried out the hydrolysis experiment of $p$-nitrophenyl acetate by using aggregates formed by other metal ions such as $\mathrm{Cu}^{2+}$ and $\mathrm{Zn}^{2+}$ to examine the exact role of metal mediated self-assembly as a catalyst for ester hydrolysis (Figure S12). These metal ions are unable to induce gelation of aggregated AM1.The kinetic parameters for the hydrolysis of $p$-nitrophenyl acetate catalyzed by $\mathrm{Cu}^{2+}$ or $\mathrm{Zn}^{2+}$ containing $\mathbf{A M 1}$ aggregates are listed in the table S2. These data clearly indicates that the rate of hydrolysisof $\mathrm{Cu}^{2+}$ or $\mathrm{Zn}^{2+}$ containingAM1aggregatesare slightly higher than the aggregated AM1alone but much less than that of ferric ion induced hydrogel of AM1.Therefore it can be stated that the kinetics of hydrolysis for $\mathrm{Cu}^{2+} / \mathrm{Zn}^{2+}$ ion containing aggregated AM1 is much slower than that of ferric ion containing complex. The exact reason for this type of ion specificity during catalysis is yet to be explored properly. The metal ion $\mathrm{Cu}^{2+} \mathrm{Zn}^{2+} / \mathrm{Fe}^{3+}$ generally stabilized the transition state of substrate during the process of hydrolysis and that can be reason for higher rate of hydrolysis observed for $\mathrm{Cu}^{2+} / \mathrm{Zn}^{2+}$ containing AM1 aggregates than amphiphileAM1 itself.We performed another hydrolysis experiment of $p$ nitrophenyl acetate by using ferric ion based histidine complex (Fe-Histidine) (Figure S13). Histidine forms a water soluble complex with $\mathrm{Fe}^{3+}$ ions. The obtained kinetic parameter is listed in thetable S2. It was observed that the rate of reaction of ferric ion based histidine complex was very much lower than aggregated $\mathbf{A M 1}$ as well as $\mathrm{Cu}^{2+} \mathrm{Zn}^{2+} / \mathrm{Fe}^{3+}$ ion induced $\mathbf{A M 1}$. So, we can conclude that peptide based self-assemblyplays an important role to catalyze the ester group rather than a non self-assembled material. 
(a)

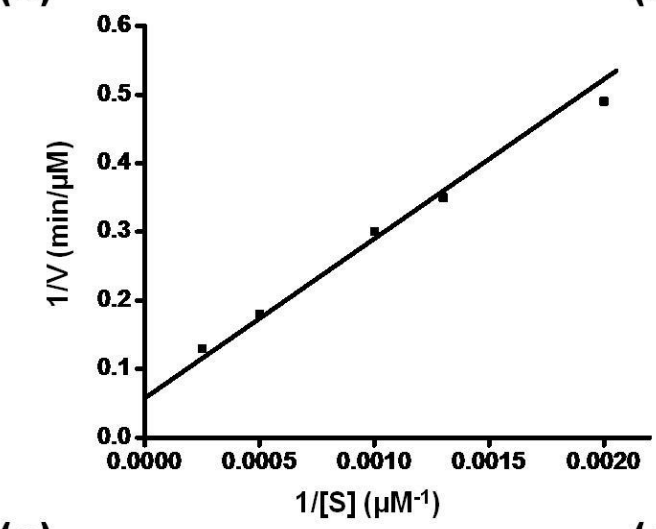

(c)

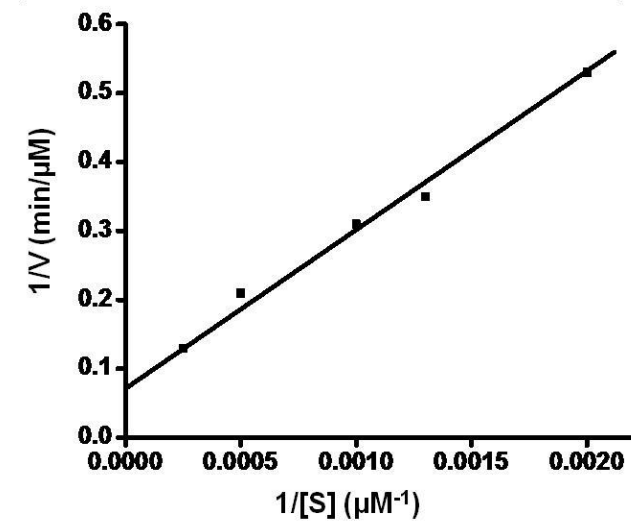

(b)

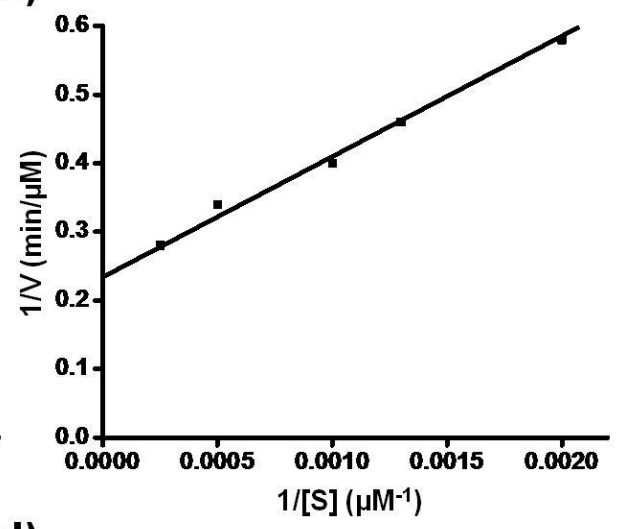

(d)

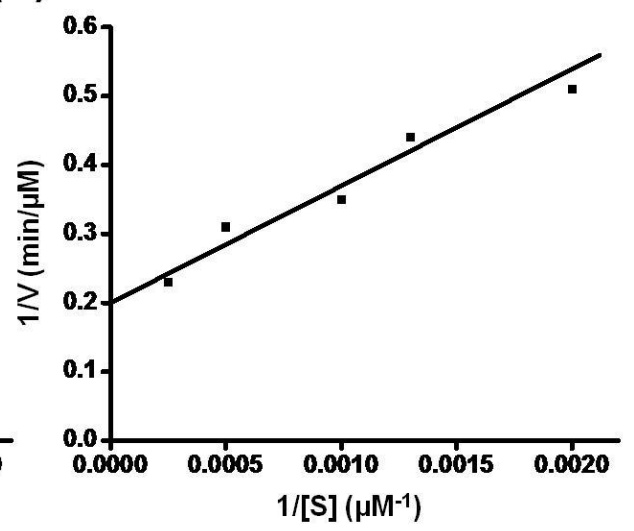

Figure 8: Lineweaver-Burk plot for hydrolysis of p-nitrophenyl butyrate (PNPB) catalyzed by (a) ferric ion based hydrogel, (b) aggragatedAM1 and hydrolysis of p-nitrophenyloctanoate (PNPO) catalyzed by (c) ferric ion based hydrogel, (d) aggragatedAM1 
Table 1: Obtained kinetic parameters for the hydrolysis of $p$-nitrophenyl acetate (PNPA), $p$ nitrophenyl butyrate (PNPB) and p- nitrophenyloctanoate (PNPO) in presence of aggregated AM1 and Fe-AM1 as catalysts.

\begin{tabular}{|c|c|c|c|}
\hline & $\begin{array}{l}K_{\text {cat }} \\
\left(\mathbf{s}^{-1}\right)\end{array}$ & $\begin{array}{c}\mathrm{K}_{\mathrm{M}} \\
(\mathbf{m M})\end{array}$ & $\begin{array}{l}K_{\text {cat }} / K_{M} \\
\left(M^{-1} s^{-1}\right)\end{array}$ \\
\hline $\begin{array}{c}\text { Aggregated AM1 } \\
\text { (p-nitrophenyl } \\
\text { acetate })(P N P A)\end{array}$ & $(1.27 \pm 0.09) \times 10^{-3}$ & $1.43 \pm 0.21$ & $0.89 \pm 0.06$ \\
\hline $\begin{array}{c}\boldsymbol{F e}-\boldsymbol{A M 1} \\
(p-n i t r o p h e n y l \\
\text { acetate })(P N P A)\end{array}$ & $(2.82 \pm 0.13) \times 10^{-2}$ & $45.12 \pm 1.26$ & $0.63 \pm 0.03$ \\
\hline $\begin{array}{c}\text { Aggregated AM1 } \\
\text { (p-nitrophenyl } \\
\text { butyrate })(P N P B)\end{array}$ & $(0.71 \pm 0.05) \times 10^{-3}$ & $0.75 \pm 0.06$ & $0.95 \pm 0.22$ \\
\hline $\begin{array}{c}\text { Fe-AM1 } \\
(p \text {-nitrophenyl } \\
\text { butyrate })(P N P B)\end{array}$ & $(0.30 \pm 0.11) \times 10^{-2}$ & $4.07 \pm 0.33$ & $0.75 \pm 0.09$ \\
\hline $\begin{array}{c}\text { Aggregated AM1 } \\
(p- \\
\text { nitrophenyloctanoate })(P N P O)\end{array}$ & $(0.82 \pm 0.12) \times 10^{-3}$ & $0.77 \pm 0.08$ & $0.94 \pm 0.17$ \\
\hline $\begin{array}{c}\mathbf{F e}-\boldsymbol{A M 1} \\
(p- \\
\text { nitrophenyloctanoate })(P N P O)\end{array}$ & $(0.24 \pm 0.15) \times 10^{-2}$ & $3.32 \pm 0.24$ & $0.73 \pm 0.11$ \\
\hline
\end{tabular}




\section{Conclusion}

We investigated metal-ion triggered hydrogelation of a S-histidine based amphiphile exhibiting esterase-like activity as observed for a series of $p$-nitrophenyl esters $\left(n_{c}=0,2,6\right)$. To the best of our knowledge this is the first report on histidine containing metallogels coupled to a synthetic amphiphile. Furthermore, the metal-ion induced self-assembly significantly influences the esterase activities. These parallels in-vitro studies on metal-containing enzymes in which the metal-ion acts as a cofactor for achieving full enzyme activity.

\section{ASSOCIATED CONTENT}

Supporting Information. The supporting information contains, Instrumentation, Methods, Details of synthesis and characterization of tested molecule AM1, Characterization of gels (Tables S1 and S2), FT-IR (Figures S4 and S5), SAXS, a tentative molecular packing model of the gel, NMR studies of the metal ion complexes, CD, molar extinction coefficient study of $p$ nitrophenol, Lineweaver-Burk plot for the hydrolysis in presence and absence of $\mathrm{Fe}^{3+}$ ionsand Figures S1-S13.

\section{Acknowledgements}

K.G. gratefully acknowledges CSIR, New Delhi, India for financial assistance. K.B. and A.B. acknowledge IACS, India and D.B thanks to UGC for financial support. We also kindly acknowledge Mr. Krishna S. Das for carrying out the rheological experiment. V.C. and I. W. Hamley thank EPSRC for the award of a Platform grant (EP/L020599/1) and Diamond for the award of beamtime (ref.SM17118-1) and Nathan Cowieson, Charlotte Edwards-Gayle and Jessica Hutchinson for assistance. 


\section{NOTES:}

The authors declare no competing financial interest.

Mercuric chloride is the only hazardous material that has been used in the work. The CAS no of the material is 7487-94-7 and the corresponding hazard code is, "Signal word (GHS-US) : Danger Hazard statements (GHS-US) : H300+H310 - Fatal if swallowed or in contact with skin.”

\section{REFERENCES}

(1) Du, X.; Zhou, J.; Shi, J.; Xu, B. SupramolecularHydrogelators and Hydrogels: From Soft Matter to Molecular Biomaterials. Chem. Rev.2015, 115, 13165-13307.

(2) Vemula, P. K.; John, G. Crops: A Green Approach toward Self-Assembled Soft Materials. Acc. Chem. Res. 2008, 41, 769-782.

(3) Raeburn, J.; Adams, D. J. Multicomponent Low Molecular Weight Gelators. Chem.Commun. 2015, 51, 5170-5180.

(4) Amabilino, D. B.; Smith, D. K.; Steed, J. W. Supramolecular Materials. Chem. Soc. Rev. 2017, 46, 2404-2420

(5) Weiss, R. G. The Past, Present, and Future of Molecular Gels. What Is the Status of the Field, and Where Is It Going? J. Am. Chem. Soc. 2014, 136, 7519-7530.

(6) Das, T.; Häring, M.; Haldar, D.; Díaz D. D. Phenylalanine and Derivatives as Versatile Low-molecular-Weight Gelators: Design, Structure and Tailored Function. Biomater. Sci., 2018, 6, 38-59.

(7) Datta, S.; Deya, N.; Bhattacharya, S. Electrochemical Probing of Hydrogelation Induced by the Self-assembly of a Donor-Acceptor Complex Comprising Pyranine and Viologen. Chem. Commun., 2017, 53, 2371-2374 
(8) Kumar, P.; Soumya, Sivalingam.; Prasad, Edamana. Enhanced Resonance Energy Transfer and White-Light Emission from Organic Fluorophores and Lanthanides in Dendron-based Hybrid Hydrogel. ACS Appl. Mater. Interfaces2016, 8, 8068-8075.

(9) Miravet, J. F.; Escuder, B. CHAPTER 5 Molecular Gels as Containers for Molecular Recognition, Reactivity and Catalysis; 2014.

Basu, K.; Baral, A.; Basak, S.; Dehsorkhi, A.; Nanda, J.; Bhunia, D.; Ghosh, S.; Castelletto, V.; Hamley, I. W.; Banerjee, A. Peptide Based Hydrogels for Cancer Drug Release: Modulation of Stiffness, Drug Release and Proteolytic Stability of Hydrogels by Incorporating D -Amino Acid Residue(S). Chem. Commun.2016, 52, 5045-5048.

(11) Ischakov, R.; Adler-Abramovich, L.; Buzhansky, L.; Shekhter, T.; Gazit, E. Peptide-Based Hydrogel Nanoparticles as Effective Drug Delivery Agents. Bioorganic Med. Chem. 2013, 21, 3517-3522.

$$
\text { Li, J.; Mooney, D. J. Designing Hydrogels for Controlled Drug Delivery. Nat. }
$$
Rev. Mater.2016, 1, 16071.

Chivers, P. R. A.; Smith, D. K. Spatially-Resolved Soft Materials for Controlled Release - Hybrid Hydrogels Combining a Robust Photo-Activated Polymer Gel with an Interactive Supramolecular Gel. Chem. Sci.2017, 8, 7218-7227.

Castelletto, V.; McKendrick, J. E.; Hamley, I. W.; Olsson, U.; Cenker, C. PEGylated Amyloid Peptide Nanocontainer Delivery and Release System. Langmuir2010, 26, 11624-11627.

Basu, K.; Nandi, N.; Mondal, B.; Dehsorkhi, A.; Hamley, I. W.; Banerjee, A. Peptide-Based Ambidextrous BifunctionalGelator: Applications in Oil Spill Recovery 
and Removal of Toxic Organic Dyes for Waste Water Management. Interface Focus 2017, 7, 20160128.

$$
\text { Knerr, P. J.; Branco, M. C.; Nagarkar, R.; Pochan, D. J.; Schneider, J. P. Heavy }
$$

Metal Ion Hydrogelation of a Self-Assembling Peptide via Cysteinyl Chelation. J. Mater.

Chem. 2012, 22, 1352-1357.

$$
\text { Okesola, B. O.; Smith, D. K. Applying Low-Molecular Weight }
$$

SupramolecularGelators in an Environmental Setting - Self-Assembled Gels as Smart Materials for Pollutant Removal. Chem. Soc. Rev. 2016, 45, 4226-4251.

Owoseni, O.; Zhang, Y.; Omarova, M.; Li, X.; Lal, J.; McPherson, G. L.;

Raghavan, S. R.; Bose, A; John, V. T. Microstructural Characteristics of Surfactant Assembly into a Gel-like Mesophase for Application as an Oil Spill Dispersant.J. Colloid Interface Sci.2018, 524, 4279-288

Mehrban, N.; Zhu, B.; Tamagnini, F.; Young, F. I.; Wasmuth, A.; Hudson, K. L.; Thomson, A. R.; Birchall, M. A.; Randall, A. D.; Song, B.; Song, B.;Woolfson, D. N.; Functionalized $\alpha$-Helical Peptide Hydrogels for Neural Tissue Engineering. ACS Biomater. Sci. Eng.2015, 1, 431-439. Zhao, F.; Ma, M. L.; Xu, B. Molecular Hydrogels of Therapeutic Agents. Chem. Soc. Rev.2009, 38, 883-891.

Das, S.; Jacob, R. S.; Patel, K.; Singh, N.; Maji, S. K. Amyloid Fibrils : Versatile Biomaterials for Cell Adhesion and Tissue Engineering Applications. Biomacromolecules2018, 19, 1826-1839. 
Containing Nanofibers, Nanosheets, and Nanoparticles: Modulation of the Rheological Property and Catalysis. Angew. Chemie - Int. Ed.2013, 52, 5041-5045.

$$
\text { Roy, S.; Basu, K.; Gayen, K.; Panigrahi, S.; Mondal, S.; Basak, D.; Banerjee, A. }
$$

$\mathrm{TiO}_{2}$ Nanoparticles Incorporated Peptide Appended PeryleneBisimide-Based Nanohybrid System: Enhancement of Photo-Switching Behavior. J. Phys. Chem. C2017, 121, 54285435.

Chen, X.; Wang, Y.; Chai, R.; Xu, Y.; Li, H.; Liu, B. Luminescent LanthanideBased Organic/Inorganic Hybrid Materials for Discrimination of Glutathione in Solution and within Hydrogels. ACS Appl. Mater. Interfaces2017, 9, 13554-13563.

Heuser, T.; Weyandt, E.; Walther, A. Biocatalytic Feedback-Driven Temporal Programming of Self-Regulating Peptide Hydrogels. Angew. Chemie - Int. Ed.2015, 54, $13258-13262$.

(26) Singh, N.; Kumar, M.; Miravet, J. F.; Ulijn, R. V.; Escuder, B. Peptide-Based Molecular Hydrogels as Supramolecular Protein Mimics. Chem. - A Eur. J.2017, 23, 981-993.

Wang, H.; Gu, H.; Chen, Z.; Shang, L.; Zhao, Z.; Gu, Z.; Zhao, Y. Enzymatic Inverse Opal Hydrogel Particles for Biocatalyst. ACS Appl. Mater. Interfaces2017, 9, $12914-12918$. Tomasini, C.; Castellucci, N. Peptides and Peptidomimetics That Behave as Low Molecular Weight Gelators. Chem. Soc. Rev.2013, 42, 156-172. Babu, P.; Sangeetha, N. M.; Maitra, U. Supramolecular Chemistry of Bile Acid Derivatives: Formation of Gels. Macromol. Symp.2006, 241, 60-67. 

Alkyloxybenzoyl)-L-Histidine Exhibiting pH-Modulated Properties. Langmuir2010, 26, $7761-7767$.

(31) Pasc, A.; Gizzi, P.; Dupuy, N.; Parant, S.; Ghanbaja, J.; Gérardin, C. Microscopic and Macroscopic Anisotropy in Supramolecular Hydrogels of Histidine-Based Surfactants. Tetrahedron Lett.2009, 50, 6183-6186.

Häringa, M.; Díaz D. D.SupramolecularMetallogels with Bulk Self-healing Properties Prepared by in Situ Metal Complexation. Chem. Commun., 2016, 52, 1306813081

Piepenbrock, M.-O. M.; Clarke, N.; Steed, J. W. Rheology and Silver Nanoparticle Templating in a Bis(Urea) Silver Metallogel. Soft Matter2011, 7, 24122418.

Chen, J.; Wang, T.; Liu, M. A Hydro-Metallogel of an Amphiphilic L-Histidine with Ferric Ions: Shear-Triggered Self-Healing and Shrinkage. Inorg. Chem. Front.2016, $3,1559-1565$.

Sharma, B.; Singh, A.; Sarma, T. K.; Sardana, N.; Pal, A. Chirality Control of Multi-Stimuli Responsive and Self-Healing SupramolecularMetallo-Hydrogels. New J. Chem.2018, 42, 6427-6432.

(36) Liu, Y.; Wang, T.; Li, Z.; Liu, M. Copper(II) Ion Selective and Strong AcidTolerable Hydrogels Formed by an 1-Histidine Ester Terminated Bolaamphiphile: From Single Molecular Thick Nanofibers to Single-Wall Nanotubes. Chem. Commun.2013, 49, 4767-4769. 

Metallo-Hydrogels: Tuning of the Gel Recovery Property. Chem. Commun.2014, 50, 2356-2359. Zou, R.; Wang, Q.; Wu, J.; Wu, J.; Schmuck, C.; Tian, H. Peptide Self-Assembly Triggered by Metal Ions. Chem. Soc. Rev.2015, 44, 5200-5219.

$$
\text { Araújo, M.; Díaz-Oltra, S.; Escuder, B. Triazolyl-Based Molecular Gels as }
$$
Ligands for Autocatalytic 'Click' Reactions. Chem. - A Eur. J.2016, 22, 8676-8684.

$$
\text { Jin, Q.; Zhang, L.; Cao, H.; Wang, T.; Zhu, X.; Jiang, J.; Liu, M. Self-Assembly }
$$
of Copper (II) Ion-Mediated Nanotube and Its Supramolecular Chiral Catalytic Behavior. Langmuir2011, 27, 13847-13853.

Laizure, S.C.; Herring, V.; Hu, Z.; Witbrodt, K.; Parker, R. B. The Role of Human Carboxylesterases in Drug Metabolism: Have We Overlooked Their Importance? Pharmacotherapy2013, 33, 210-222. Zaramella, D.; Scrimin, Paolo.;Prins, L. J. Self-Assembly of a Catalytic Multivalent Peptide-Nanoparticle Complex. J. Am. Chem. Soc. 2012, 134, 8396-8399.

Pengo, P.; Polizzi, S.; Pasquato, L.; Scrimin, P. Carboxylate-Imidazole Cooperativity in Dipeptide-Functionalized Gold Nanoparticles with Esterase-like Activity. J. Am. Chem. Soc.2005, 127, 1616-1617.

(44) Pieters, G.; Prins, L. J. Catalytic Self-Assembled Monolayers on Gold Nanoparticles. New J. Chem.2012, 36, 1931-1939.

$$
\text { Mikolajczak, D. J.; Heier, J. L.; Schade, B.; Koksch, B. Catalytic Activity of }
$$

Peptide - Nanoparticle Conjugates Regulated by a Conformational

Change.Biomacromolecules2017, 3557-3562. 
Ester Hydrolysis and Aldolization Prepared by Convergent Thioether Ligation. Org. Biomol. Chem.2011, 9, 7071-7084.

Darbre, T.; Reymond, J. L. Peptide Dendrimers as Artificial Enzymes, Receptors, and Drug-Delivery Agents. Acc. Chem. Res.2006, 39, 925-934.

$$
\text { Chadha, G.; Zhao, Y. Histidine-Functionalized Water-Soluble Nanoparticles for }
$$
Biomimetic Nucleophilic/General-Base Catalysis under Acidic Conditions. Org. Biomol. Chem.2013, 11, 6849-6855.

Chadha, G.; Zhao, Y. Environmental Control of Nucleophilic Catalysis in Water.

Chem. Commun.2014, 50, 2718-2720.

Singh, N.; Conte, M. P.; Ulijn, R. V; Miravet, J. F.; Escuder, B. ChemComm Insight into the Esterase like Activity Demonstrated by an Imidazole AppendedSelfassembling Hydrogelator. Chem. Commun.2015, 51, 13213-13216.

(51) Guler, M. O.; Stupp, S. I. A Self-Assembled Nanofiber Catalyst for Ester Hydrolysis. J. Am. Chem. Soc.2007, 129, 12082-12083. Huang, Z.; Guan, S.; Wang, Y.; Shi, G.; Cao, L.; Gao, Y.; Dong, Z.; Xu, J.; Luo,

Q.; Liu, J. Self-Assembly of Amphiphilic Peptides into Bio-Functionalized Nanotubes: A Novel Hydrolase Model. J. Mater. Chem. B2013, 1, 2297-2304. Zhang, C.; Xue, X.; Luo, Q.; Li, Y.; Yang, K.; Zhuang, X.; Jiang, Y.; Zhang, J.; Liu, J.; Zou, G.; Liang, X.-J. Self-Assembled Peptide Nanofibers Designed as Biological Enzymes for Catalyzing Ester Hydrolysis. ACS Nano2014, 8, 11715-11723. Duncan, K. L.; Ulijn, R. V. Short Peptides in Minimalistic Biocatalyst Design. Biocatalysis2015, 1, 67-81. 
Catalytic Activity of Histidine-Based Structured Lipopeptides for Hydrolysis Reactions in Water. $R S C A d v . \mathbf{2 0 1 5}, 5,35830-35842$. Garcia, A. M.; Kurbasic, M.; Kralj, S.; Melchionna, M.; Marchesan, S. A

Biocatalytic and Thermoreversible Hydrogel from a Histidine-Containing Tripeptide.

Chem. Commun.2017, 53, 8110-8113. Yang, X.; Wang, Y.; Qi, W.; Su, R.; He, Z. BioorganometallicFerrocene-

TripeptideNanoemulsions. Nanoscale2017, 9, 15323-15331. Zhang, C.; Shafi, R.; Lampel, A.; MacPherson, D.; Pappas, C. G.; Narang, V.;

Wang, T.; Maldarelli, C.; Ulijn, R. V. Switchable Hydrolase Based on Reversible Formation of Supramolecular Catalytic Site Using a Self-Assembling Peptide. Angew. Chemie - Int. Ed.2017, 129, 14703-14707.

$$
\text { Rufo, C. M.; Moroz, Y. S.; Moroz, O. V.; Stöhr, J.; Smith, T. A.; Hu, X.; }
$$

DeGrado, W. F.; Korendovych, I. V. Short Peptides Self-Assemble to Produce Catalytic Amyloids. Nat. Chem.2014, 6, 303-309. Paul, S.; Gayen, K.; Nandi, N.; Banerjee, A. Carbon Nanodot-Induced Gelation of a Histidine-Based Amphiphile: Application as a Fluorescent Ink, and Modulation of Gel Stiffness. Chem. Commun.2018, 54, 4341-4344.

(61) Naskar, J.; Palui, G.; Banerjee, A. Tetrapeptide-Based Hydrogels: For Encapsulation and Slow Release of an Anticancer Drug at Physiological pH.J. Phys. Chem. B2009, 113, 11787-11792. Goren, H. J.; Fridkin, M. The Hydrolysis of $p$-Nitrophenylacetate in WaterEur. J. Biochem. 1974, 41, 263-272. 


\section{Graphical Abstract}

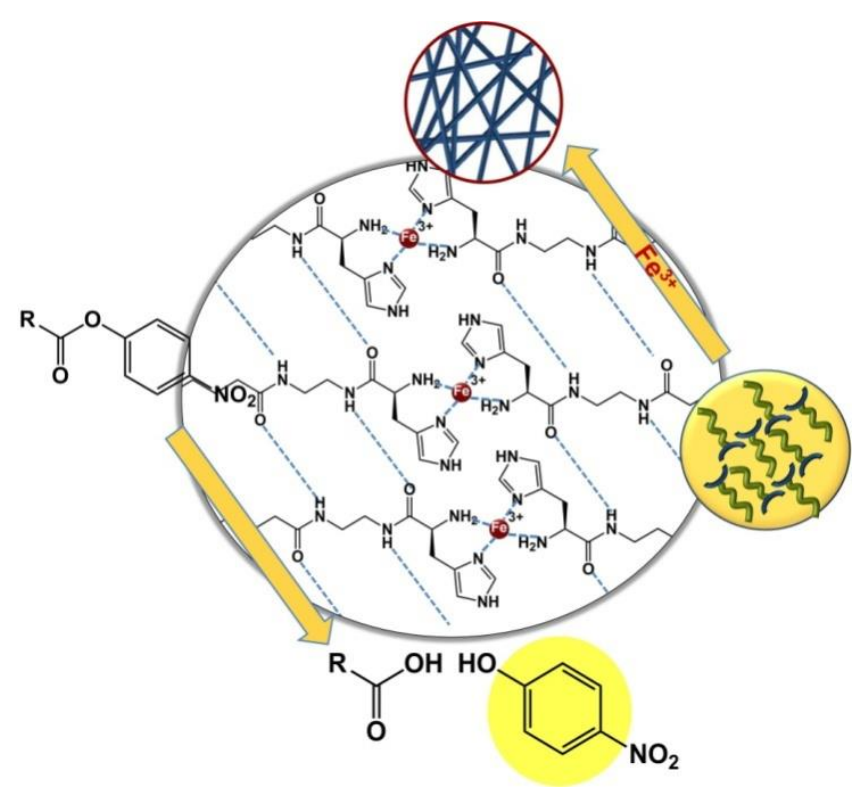

